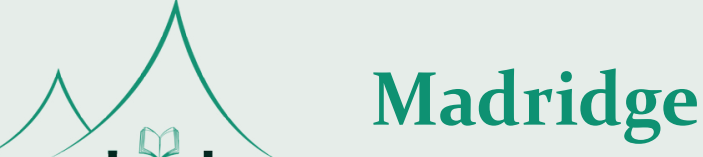 \\ madridge Journal of Otorhinolaryngology \\ interconnecting Scientific World
}

Research Article

Open Access

\section{Subjective and Objective Outcome Evaluation of FESS with and without Mitomycin C: A Randomized Control Trial}

\author{
Harugop AS ${ }^{\star}$, Mudhol RS, Dharmishta Kaku, Vishnu V and Suhasini H \\ Department of ENT and HNS, Jawarharlal Nehru Medical College, Belagavi, India
}

\section{Article Info}

\section{*Corresponding author: \\ AS Harugop}

Department of ENT and HNS

Jawarharlal Nehru Medical College

Belagavi

India

E-mail: aharugop@yahoo.com; vishnuvpillai979@gmail.com

Received: November 30, 2017

Accepted: February 27, 2018

Published: March 6, 2018

Citation: Harugop AS, Mudhol RS, Kaku $D$, Vishnu V, Suhasini $H$. Subjective and Objective Outcome Evaluation of FESS with and without Mitomycin C: A Randomized Control Trial. Madridge J Otorhinolaryngol. 2018; 3(1): 31-36.

doi: $10.18689 / \mathrm{mjol}-1000106$

\section{Copyright: ๑ 2018 The Author(s). This work is licensed under a Creative Commons Attribution 4.0 International License, which permits unrestricted use, distribution, and reproduction in any medium, provided the original work is properly cited.}

Published by Madridge Publishers

\begin{abstract}
Objective: To determine the efficacy of Mitomycin C (MMC) in symptomatic improvement in outcome in patients of chronic Rhinosinusitis (CRS) after Endoscopic Sinus Surgery (ESS/ FESS) using SNOT-20 and its domains.
\end{abstract}

Study design: Randomized Clinical Trial.

Materials and Methods: Total 150 patients between" May 2011 to July 2014 with clinical and $\mathrm{CT}$ features of chronic rhino sinusitis, not responding to maximal medical treatment, were subjected to endoscopic sinus surgery (ESS/FESS).75 patients were included in Group $\mathrm{A}$ (Interventional-MMC) and 75 patients in group B (Control-Saline). There were 30 unilateral and 45 bilateral, thus 120 operative sides in each group. Follow up visits were done at weekly for first two weeks and then at $1^{\text {st }}, 2^{\text {nd }}$ and $3^{\text {rd }}$ month and subjective parameters evaluated included total score and individual symptom score of 4 symptoms-Facial pain/pressure, Nasal block, Discharge and Hyposmia, SNOT-20 score and its 4 domains- Rhinologic domain, Ear \& facial domain, Sleep and Psychologic domains.

Results: The symptomatic improvement found in present study was slightly better in Group-A than Group-B. There was significant difference between the group A \& B with respect to change in SNOT total score from pre to post-operative period $(p<0.001)$. Group A showed better improvement in rhinologic domain, whereas group B showed better improvement in ear and facial domain. In sleep and psychologic domains, both the groups showed similar post operative improvement. (p.0.05).

Conclusion: Symptomatically, MMC shown better improvement in relieving nasal obstruction and facial pain but did not had much role in nasal discharge and hyposmia. The symptomatic outcome signifies the efficacy of FESS without any significant role of MMC.

Keywords: Chronic rhino sinusitis, SNOT 20 and its domains, Mitomycin C

\section{Introduction}

Chronic rhino sinusitis is a common disease of the nose and paranasal sinuses globally with lifetime incidence of about $15 \%$ [1]. The disease is on the rise in our country due to increasing pollution, allergic factors, industrial fumes in the urban areas [2].

Endoscopic Sinus Surgery (ESS/FESS) is now a well established treatment for chronic rhino sinusitis which is not responding to medical line of management [3].

Mitomycin $C$ is an antibiotic-antineoplastic agent first isolated from Streptomyc scaespitosus in 1958 [4]. It inhibits the synthesis of DNA through a bi functional alkylation that leads to the crossing of double helical strands not allowing neoplastic cells to proliferate. Higher dosages of MMC inhibit the synthesis of RNA and proteins, and it has 
been used for many years now in oncology care. It inhibits scarring when used topically [5].

The Sino-Nasal Outcome Test 20 (SNOT-20) is one of the most widely used quality-of-life instruments for sino nasal conditions $[6,7,8]$ and is intended for populations of people with rhino sinusitis. This instrument assesses a broad range of health and health-related quality-of-life problem including functional limitations, physical problems and emotional consequences.

Brown et.al used a population of patients who had presented to an otolaryngologist in the United Kingdom and had completed pre- and postoperative SNOT-20 surveys related to surgery for nasal polyps or non polypoid chronic rhino sinusitis. Their validation studies supported dividing the SNOT-20 into four domains: a rhino logic, ear and facial symptoms, sleep, and psychological domain. The rhino logic domain consists of five questions: need to blow nose, sneezing, runny nose, postnasal discharge, and thick nasal discharge. The ear and facial symptoms domain consists of four questions: ear fullness, dizziness, ear pain, and facial pain/ pressure. The sleep domain consists of three questions: difficulty falling asleep, waking up at night, and lack of a good night's sleep. The psychological domain consists of six questions: fatigue, reduced productivity, reduced concentration, frustration/ restlessness/irritability, sadness, and embarrassment [9].

Symptomatic outcome analysis using SNOT and it's four domains will help to understand post-interventional quality of life impact for CRS and will help clinician for effective counseling. Hence, this study was undertaken to evaluate Subjective outcome in Chronic Rhino sinusitis Patients after Mitomycin C application in Endoscopic Sinus Surgery (ESS/ FESS) using SNOT-20 and its Domains.

\section{Materials and Methods}

\section{Study duration and source of data}

Patients attending the OPD/IPD of KLES Dr. Prabhakar Kore Hospital and MRC, Belagavi, a tertiary referral hospital were included for the study. The patients with symptoms suggestive of CRS (with or without NP) as per rhino sinusitis task force (RSTF) -2007 criteria were evaluated by their 4 major symptoms, subjected to SNOT-20 score, CT scan of para-nasal sinuses (PNS), not responding to maximal medical treatment, were subjected to endoscopic sinus surgery (ESS/ FESS). Total 150 patients between" May 2011 to July 2014 were included in the study. Patients with acute exacerbation of symptoms, established asthma, suspected cystic fibrosis, patients refusing to undergo CT scan, patients with established or impending complications, patients refusing endoscopic surgery and patients with prior sinus surgeries were excluded from the study.

\section{Ethical approval}

The study was approved by the institutional ethical committee. The research was approved as per the letter no KLEU/D/6564-67. Before ESS/FESS written and informed consent was taken from all patients.
Study design: Randomized clinical trial

\section{Methodology}

150 patients of the study was randomized into Group $A$ having 75 patients (Interventional- $\mathrm{MMC}$ ) and Group B (Control-Saline). There were 30 unilateral and 45 bilateral, thus 120 operative sides in each group. Out of 150 patients, 133 were operated under local anaesthesia and 17 patients ( 8 in group-A and 9 in group-B) who were not cooperative were operated under general anesthesia. Broadly the FESS included uncinectomy, middle meatal antrostomy with maxillary sinus clearance, anterior or total ethmoidal, sphenoidal and frontal recess clearance.

After the completion of procedure in group- $A$, a cotton ribbon wick soaked in $1 \mathrm{ml}$ of Mitomycin-C (MMC) in a concentration of $0.4 \mathrm{mg} / \mathrm{ml}$ and in Group- $B$, a cotton ribbon wick soaked in $1 \mathrm{ml}$ of $0.9 \%$ normal saline was placed in the nasal cavity.

At the end of surgery, light anterior nasal packing was done using ribbon gauze soaked with steroid and antibiotic ointment. All patients were discharged the day after surgery after pack removal on oral antibiotic for two weeks, nasal saline washing three times a day, topical steroid spray twice a day for three weeks in each nasal cavity.

Follow up visits were done at weekly for first two weeks and then at $1^{\text {st }}, 2^{\text {nd }}$ and $3^{\text {rd }}$ month andsubjective parameters evaluated included total score and individual symptom score of 4 symptoms-Facial pain/pressure, Nasal block, Discharge and Hyposmia\&SNOT-20 score and its 4 domains- Rhinologic domain, Ear \& facial domain, Sleep and Psychologic domains. On $3^{\text {rd }}$ month follow up 4 major symptoms and SNOT were taken up for analysis.

\section{Statistical analysis}

The data were statistically analyzed by applying nonparametric tests i.e. Mann-Whitney U-test was used between the groups at pre and post test. The Wilcoxon matched pairs test by ranks was used to assess the difference between pre and post op in each group for every parameters. This was statistically analyzed with SPSS 20.00 version software. The statistical significance was set at statistical level of significance $(p<0.05)$.

\section{Results}

In both group $A$ and group $B$ number of patients with unilateral involvement were 30 and bilateral involvement were 45 and thus total operative sides in each group were 120 . The age range in group $A$ and group $B$ was 17-66 and the mean age in group $A$ (MMC group) was 34.5 and in group $B$ (NS group) was 36.6 and there was equal distribution of patients by age between the two groups (Chi square value 1.814, $p=0.764$ ). Out of 150 patients, 98 were males and 52 were females. Further out of 98 males, $61.33 \%$ were in group $A$ and $69.33 \%$ were in group B. The difference in distribution of male and female in two groups was not significant (Chi square value 1.0601, $\mathrm{p}=0.3033$ ). 


\section{Total Score}

Percentage of change from pre-operative to post-operative total symptom score in group $A$ was $78.56 \%$ ( $Z=7.5248, p<0.001)$ and in group $B$ it was $74.93 \%(Z=7.5248, p<0.001)$, which was significant. The symptomatic improvement was slightly better in Group-A than in Group-B. (Table-1, Graph-1)

\section{- $\quad$ Facial pain / pressure:}

Postoperatively $86.57 \%$ patients in group $A(Z=6.6800$, $p<0.001)$ and $75.97 \%$ in group- $B(Z=6.8463, p<0.001)$ showed significant improvement with respect to facial pain (table-1, graph-1).The difference between two group A \& group B with respect to improvement in facial pain from pre-operative to post-operativewasstatistically significant $(Z=-4.5650, p<0.001)$ (Table-2). and group-A had better improvement in facial pain.

\section{- Nasal Obstruction}

Postoperatively $79.47 \%$ patients had significant improvement in group $A(Z=7.1674, p<0.001)$ and $74.39 \%$ in group $B(Z=7.2136$, $p<0.001$ ) (table-1, graph-1). The difference between group $A$ and group $B$ with respect to nasal obstruction from pre- operative to post-operative was statistically significant $(Z=$ -2.5484, $p<0.05$, table-2). Group-A had better improvement in nasal obstruction than group $B$.

\section{- Nasal Discharge- Anterior / Posterior}

Postoperatively $71.83 \%$ patients had significant improvement in group $A(Z=5.9052, p<0.001)$ and $75 \%$ in group $B(Z=5.3028, p<0.001)$ (table-1, graph-1). The difference between group $A$ and group $B$ with respect to nasal discharge from pre-operative to post-operative was statistically not significant $(Z=-0.6954, p=0.4868$, table-2). Group- $B$ had better improvement in nasal discharge.

\section{- Hyposmia}

The group-A showed $22.22 \%$ smell improvement postoperatively $(Z=1.8257, p=0.0679)$ and in group- $B$ the improvement was $57.14 \%(Z=1.6036, p=0.1088)$ (Table-1, graph-1). The difference between group $A$ and group $B$ with respect to hyposmia from pre-operative to post-operative was statistically not significant $(Z=-0.7160, p=0.4740$, Table-2) and group-B had better improvement in hyposmia than group-A.

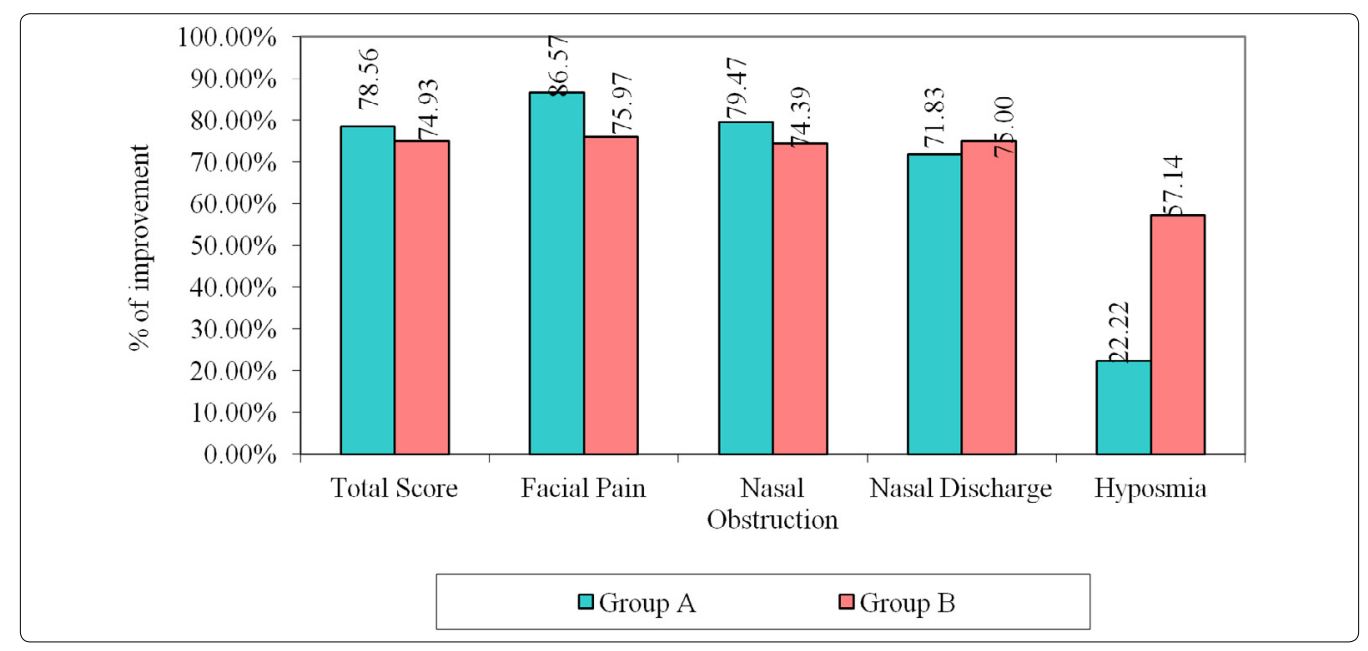

Graph 1. Symptomatic improvement in 2 groups

Table 1. Comparison of pre and post- operative symptoms score and four main symptoms scores in Group A and group B by Wilcoxon matched pairs test $\left({ }^{*} p<0.05\right)$

\begin{tabular}{|c|c|c|c|c|c|c|c|c|c|}
\hline Groups & Variables & Time & Mean & Std.Dv. & Mean Diff. & SD Diff. & $\%$ of change & Z-value & P-value \\
\hline \multirow{10}{*}{ Group A } & \multirow{2}{*}{ Total } & Pre op & 8.52 & 2.46 & & & & & \\
\hline & & Post op & 1.83 & 0.95 & 6.69 & 1.96 & 78.56 & 7.5248 & $0.00001^{*}$ \\
\hline & \multirow{2}{*}{ Facial pain/pressure } & Pre op & 2.88 & 1.66 & & & & & \\
\hline & & Post op & 0.39 & 0.49 & 2.49 & 1.41 & 86.57 & 6.6800 & $0.00001^{*}$ \\
\hline & \multirow{2}{*}{ Nasal Obstruction } & Pre op & 3.51 & 1.31 & & & & & \\
\hline & & Post op & 0.72 & 0.53 & 2.79 & 1.13 & 79.47 & 7.1674 & $0.00001^{*}$ \\
\hline & \multirow{2}{*}{ Nasal Discharge/ Ant / Post } & Pre op & 1.89 & 1.64 & & & & & \\
\hline & & Post op & 0.53 & 0.50 & 1.36 & 1.22 & 71.83 & 5.9052 & $0.00001^{*}$ \\
\hline & \multirow{2}{*}{ Hyposmia } & Pre op & 0.24 & 0.79 & & & & & \\
\hline & & Post op & 0.19 & 0.69 & 0.05 & 0.23 & 22.22 & 1.8257 & 0.0679 \\
\hline \multirow{10}{*}{ Group B } & \multirow{2}{*}{ Total } & Pre op & 9.31 & 2.65 & & & & & \\
\hline & & Post op & 2.33 & 0.78 & 6.97 & 2.09 & 74.93 & 7.5248 & $0.00001^{*}$ \\
\hline & \multirow{2}{*}{ Facial pain/pressure } & Pre op & 3.44 & 1.65 & & & & & \\
\hline & & Post op & 0.83 & 0.42 & 2.61 & 1.27 & 75.97 & 6.8463 & $0.00001^{*}$ \\
\hline & \multirow{2}{*}{ Nasal Obstruction } & Pre op & 3.85 & 1.35 & & & & & \\
\hline & & Post op & 0.99 & 0.45 & 2.87 & 1.11 & 74.39 & 7.2136 & $0.00001^{*}$ \\
\hline & \multirow{2}{*}{ Nasal Discharge/ Ant / Post } & Pre op & 1.92 & 1.99 & & & & & \\
\hline & & Post op & 0.48 & 0.55 & 1.44 & 1.51 & 75.00 & 5.3028 & $0.00001^{*}$ \\
\hline & \multirow{2}{*}{ Hyposmia } & Pre op & 0.09 & 0.47 & & & & & \\
\hline & & Post op & 0.04 & 0.20 & 0.05 & 0.28 & 57.14 & 1.6036 & 0.1088 \\
\hline
\end{tabular}


Table 2. Comparison of two groups with pre and post operative symptom scores by Mann-Whitney $U$ test

\begin{tabular}{|c|c|c|c|c|c|c|c|c|c|c|}
\hline \multirow{2}{*}{ Variables } & \multirow[b]{2}{*}{ Time } & \multicolumn{3}{|c|}{ Group A } & \multicolumn{3}{|c|}{ Group B } & \multirow{2}{*}{ U-value } & \multirow{2}{*}{ Z-value } & \multirow{2}{*}{ p-level } \\
\hline & & Mean & SD & Mean rank & Mean & Std.Dev. & Mean rank & & & \\
\hline \multirow{2}{*}{$\begin{array}{l}\text { Symptom } \\
\text { Total score }\end{array}$} & Pre op & 8.52 & 2.46 & 68.71 & 9.31 & 82.29 & 82.29 & 2303.00 & -1.9151 & 0.0555 \\
\hline & Post op & 1.83 & 0.95 & 63.31 & 2.33 & 87.69 & 87.69 & 1898.00 & -3.4374 & $0.0006^{*}$ \\
\hline \multirow{2}{*}{\begin{tabular}{|l} 
Facial pain/ \\
Pressure
\end{tabular}} & Pre op & 2.88 & 1.66 & 65.29 & 3.44 & 85.71 & 85.71 & 2046.50 & -2.8792 & $0.0040^{*}$ \\
\hline & Post op & 0.39 & 0.49 & 59.31 & 0.83 & 91.69 & 91.69 & 1598.00 & -4.5650 & $0.00001^{*}$ \\
\hline \multirow{2}{*}{$\begin{array}{l}\text { Nasal } \\
\text { Obstruction }\end{array}$} & Pre op & 3.51 & 1.31 & 67.05 & 3.85 & 83.95 & 83.95 & 2178.50 & -2.3830 & $0.0172^{*}$ \\
\hline & Post op & 0.72 & 0.53 & 66.46 & 0.99 & 84.54 & 84.54 & 2134.50 & -2.5484 & $0.0108^{*}$ \\
\hline \multirow{2}{*}{$\begin{array}{l}\text { Nasal Discharge/ } \\
\text { Ant / Post }\end{array}$} & Pre op & 1.89 & 1.64 & 74.02 & 1.92 & 76.98 & 76.98 & 2701.50 & -0.4172 & 0.6765 \\
\hline & Post op & 0.53 & 0.50 & 77.97 & 0.48 & 73.03 & 73.03 & 2627.50 & -0.6954 & 0.4868 \\
\hline \multirow{2}{*}{ Hyposmia } & Pre op & 0.24 & 0.79 & 77.97 & 0.09 & 73.03 & 73.03 & 2627.00 & -0.6972 & 0.4857 \\
\hline & Post op & 0.19 & 0.69 & 78.04 & 0.04 & 72.96 & 72.96 & 2622.00 & -0.7160 & 0.4740 \\
\hline
\end{tabular}

\section{Symptomatic outcome analysis using} SNOT-20 and its four domains: (Table-3 \& 4, Graph-2)

\section{SNOT-20 total score:}

- $\quad$ The SNOT-20 total score, the percentage of improvement from preoperative to postoperative period in group $A$ was $65.19 \%(Z=7.5248, p<0.001)$ and in group $B$ it was 67.34\% ( $Z=7.5248, p<0.001$, table-3). However, the difference between the group A \& B with change in SNOT total score from pre to post-operative was statistically significant $(z=-3.6892, p<0.001$, table-4).

\section{- Rhinologic domain:}

As a whole, in the Rhinologic domain, the percentage of improvement in group A was 64.87\% $(Z=7.4244, p<0.001)$ and in group $B$ it was $62.24 \%(Z=7.5248, p<0.001)$. The difference between group $A$ and $B$ with change in rhinologic domain from per to post- operative period was statistically significant $(Z=-5.4502, p<0.001)$. Thus the group $A$ showed better improvement in rhinologic domain.

\section{- Ear and Facial domain:}

- In the Ear and Facial domain, the percentage of improvement in group $A$ was $69.53 \%(Z=7.3227, p<0.001)$ and in group $B$ it was $72.62 \%(Z=7.5248, p<0.001)$. The difference between group $A$ and group $B$ with change in ear and facial domain from pre to post-operative period was statistically significant $(Z=-4.5631, p<0.001)$. Group B showed better improvement than group $A$ in this domain.

\section{- Sleep domain}

In the Sleep domain, the percentage of improvement in group $A$ was $60.47 \%(Z=6.1537, p<0.001)$ and in group $B$ it was $60.06 \%(Z=6.5094, p<0.001)$. The difference between group $A$ and group $B$ with the change in this domain was not statistically significant $(Z=-0.7179, p=0.4728)$. Thus both groups showed similar post-operative improvement in sleep domain.

\section{- Psychological domain}

In the Psychological domain, the percentage of improvement seen in group $A$ was $65.19 \% \quad(Z=6.6800$, $p<0.001)$ and in group $B$ it was $77.70 \%(z=7.2196, p<0.001)$. Further, the difference between group $A$ and group $B$ with the change in psychological domain was statistically not significant $(z=-1.6238, p=0.1044)$. Thus, in psychological domain both groups showed similar improvement in postoperative period.

Table 3. Comparison of pre and post-op with SNOT and its domains scores in group A and group B by Wilcoxon matched pairs test

\begin{tabular}{|c|c|c|c|c|c|c|c|c|c|}
\hline Groups & Variables & Time & Mean & Std.Dv. & Mean Diff. & SD Diff. & $\%$ of change & Z-value & P-value \\
\hline \multirow[t]{10}{*}{ Group A } & \multirow[t]{2}{*}{ Total SNOT } & Pre op & 24.44 & 8.97 & & & & & \\
\hline & & Post op & 8.51 & 4.31 & 15.93 & 6.54 & 65.19 & 7.5248 & $<0.001$ \\
\hline & \multirow[t]{2}{*}{ Rhinological domain } & Pre op & 9.91 & 4.22 & & & & & \\
\hline & & Post op & 3.48 & 1.81 & 6.43 & 2.92 & 64.87 & 7.4244 & $<0.001$ \\
\hline & \multirow[t]{2}{*}{ Ear and facial domain } & Pre op & 5.12 & 3.24 & & & & & \\
\hline & & Post op & 1.56 & 1.30 & 3.56 & 2.39 & 69.53 & 7.3227 & $<0.001$ \\
\hline & \multirow[t]{2}{*}{ Sleep domain } & Pre op & 4.01 & 2.72 & & & & & \\
\hline & & Post op & 1.59 & 1.38 & 2.43 & 2.48 & 60.47 & 6.1537 & $<0.001$ \\
\hline & \multirow{2}{*}{$\begin{array}{l}\text { Psychological } \\
\text { Domain }\end{array}$} & Pre op & 5.40 & 4.49 & & & & & \\
\hline & & Post op & 1.88 & 1.90 & 3.52 & 3.41 & 65.19 & 6.6800 & $<0.001$ \\
\hline \multirow[t]{10}{*}{ Group B } & \multirow[t]{2}{*}{ Total SNOT } & Pre op & 33.44 & 9.01 & & & & & \\
\hline & & Post op & 10.92 & 3.77 & 22.52 & 8.49 & 67.34 & 7.5248 & $<0.001$ \\
\hline & \multirow[t]{2}{*}{ Rhinological domain } & Pre op & 14.37 & 4.03 & & & & & \\
\hline & & Post op & 5.43 & 2.05 & 8.95 & 3.23 & 62.24 & 7.5248 & $<0.001$ \\
\hline & \multirow{2}{*}{ Ear and facial domain } & Pre op & 9.25 & 2.67 & & & & & \\
\hline & & Post op & 2.53 & 1.34 & 6.72 & 2.57 & 72.62 & 7.5248 & $<0.001$ \\
\hline & \multirow[t]{2}{*}{ Sleep domain } & Pre op & 4.37 & 2.39 & & & & & \\
\hline & & Post op & 1.75 & 1.37 & 2.63 & 2.68 & 60.06 & 6.5094 & $<0.001$ \\
\hline & \multirow{2}{*}{$\begin{array}{l}\text { Psychological } \\
\text { Domain }\end{array}$} & Pre op & 5.44 & 3.65 & & & & & \\
\hline & & Post op & 1.21 & 1.08 & 4.23 & 3.59 & 77.70 & 7.2196 & $<0.001$ \\
\hline
\end{tabular}


Table 4: Comparison of Group A and Group B with pre and post- operative SNOT scores by Mann-Whitney U test

\begin{tabular}{|c|c|c|c|c|c|c|c|c|c|c|}
\hline \multirow{2}{*}{ Variables } & \multirow[t]{2}{*}{ Time } & \multicolumn{3}{|c|}{ Group A } & \multicolumn{3}{|c|}{ Group B } & \multirow{2}{*}{ U-value } & \multirow{2}{*}{ Z-value } & \multirow{2}{*}{$\mathrm{p}$-value } \\
\hline & & Mean & SD & Mean rank & Mean & Std.Dev. & Mean rank & & & \\
\hline \multirow{2}{*}{ Total SNOT } & Pre op & 24.44 & 8.97 & 55.36 & 33.44 & 95.64 & 95.64 & 1302.00 & -5.6776 & $<0.001$ \\
\hline & Post op & 8.51 & 4.31 & 62.41 & 10.92 & 88.59 & 88.59 & 1831.00 & -3.6892 & $<0.001$ \\
\hline \multirow{2}{*}{ Rhinological domain } & Pre op & 9.91 & 4.22 & 55.59 & 14.37 & 95.41 & 95.41 & 1319.50 & -5.6118 & $<0.001$ \\
\hline & Post op & 3.48 & 1.81 & 56.17 & 5.43 & 94.83 & 94.83 & 1362.50 & -5.4502 & $<0.001$ \\
\hline \multirow{2}{*}{$\begin{array}{l}\text { Ear and facial } \\
\text { domain }\end{array}$} & Pre op & 5.12 & 3.24 & 48.30 & 9.25 & 102.70 & 102.70 & 772.50 & -7.6678 & $<0.001$ \\
\hline & Post op & 1.56 & 1.30 & 59.31 & 2.53 & 91.69 & 91.69 & 1598.50 & -4.5631 & $<0.001$ \\
\hline \multirow{2}{*}{ Sleep domain } & Pre op & 4.01 & 2.72 & 71.83 & 4.37 & 79.17 & 79.17 & 2537.00 & -1.0355 & $<0.001$ \\
\hline & Post op & 1.59 & 1.38 & 72.95 & 1.75 & 78.05 & 78.05 & 2621.50 & -0.7179 & $<0.001$ \\
\hline \multirow{2}{*}{$\begin{array}{l}\text { Psychological } \\
\text { Domain }\end{array}$} & Pre op & 5.40 & 4.49 & 71.57 & 5.44 & 79.43 & 79.43 & 2518.00 & -1.1069 & $<0.001$ \\
\hline & Post op & 1.88 & 1.90 & 81.26 & 1.21 & 69.74 & 69.74 & 2380.50 & -1.6238 & $<0.001$ \\
\hline
\end{tabular}

${ }^{*} \mathrm{p}<0.05$

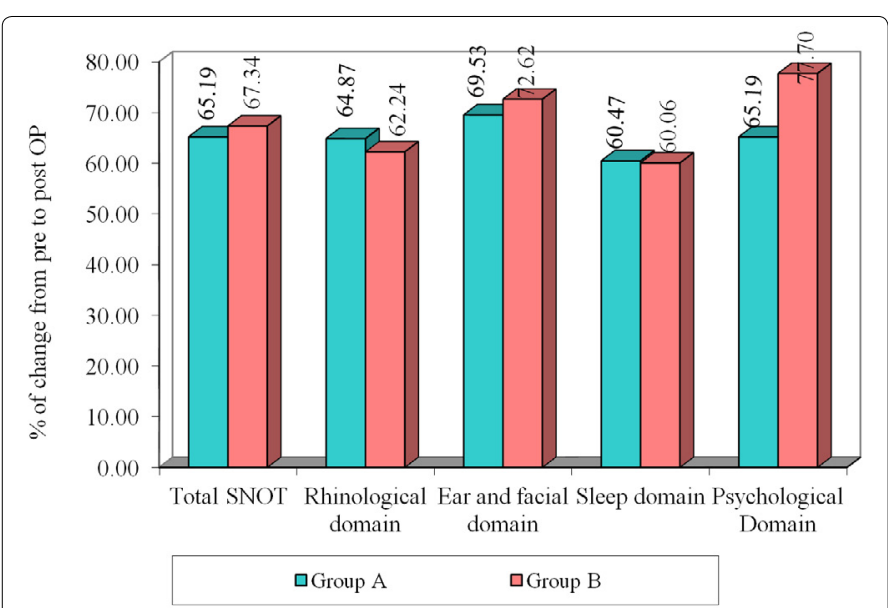

Graph 2. Comparison of improvement by SNOT-20 total score and its 4 domains in two groups

\section{Discussion}

In this study the subjective evaluation was mainly done by severity of 4 symptoms, total symptom score, scores of facial pain / pressure, nasal obstruction, nasal discharge and hyposmia, SNOT total score and four domains of SNOT namelyRhinologic, Ear \& facial, Sleep and Psychological domain.

The total symptomatic improvement found in the present study was slightly better in Group-A than in Group-B. The improvement in nasal obstruction in the present study was better in Group A (79.47\%) than in Group B (74.39\%). Similarly the facial pain also showed better improvement in Group $A$ (86.6\%) than in Group B (76\%). But the nasal discharge and hyposmia showed better improvement in Group B than Group A (table-1 \&2, graph-1).

A study by Murthy P.et al (2013) [10] showed the symptoms of facial pain, headache, nasal obstruction, nasal discharge, smell disturbance and overall discomfort improved with statistical significance $(p<0.001)$ but most improved were nasal obstruction and facial pain. National audit of sinus surgery's report was published by the Royal College of Surgeons of England, which reported rates of improvement in nasal obstruction of $84 \%$ and pain in $75 \%$. [11,12]

Net kovski J et al (2006) [13] in their study showed improvement in nasal obstruction in $87 \%$, post nasal discharge in $74.3 \%$, anterior nasal discharge in $70.5 \%$, headache in $59.4 \%$ and hyposmia in $58.7 \%$ of the patients.
A study by Hemant chopra et al (2006) [14] showed improvement in all symptoms especially nasal obstruction $(83 \%)$ and nasal discharge (86\%). Overall there was marked improvement of symptoms after FESS in 70\% patients.

A study by Venkatraman $V$ et al (2011) [15] observed statistically significant improvement in nasal obstruction and discharge in MMC side as compared to saline sides. They also showed significant improvement in nasal obstruction and nasal discharge as found in the present study.

On comparison of symptomatic improvement of the present study with various other studies (Table-5) the most improved symptoms were Nasal Obstruction, Facial Pain and Nasal Discharge and hyposmia was the least improved symptom.

Table 5. Comparison of symptomatic improvement of the present study with various other studies

\begin{tabular}{|c|c|c|c|c|}
\hline Study & $\begin{array}{c}\text { Nasal } \\
\text { Obstruction }\end{array}$ & Facial Pain & $\begin{array}{c}\text { Nasal } \\
\text { Discharge } \\
\text { (Ant/Post) }\end{array}$ & Hyposmia \\
\hline Murthy. P et al(2011) & $\begin{array}{c}\text { Most } \\
\text { Improved }\end{array}$ & $\begin{array}{c}\text { Most } \\
\text { Improved }\end{array}$ & Improved & $\begin{array}{c}\text { Least } \\
\text { improved }\end{array}$ \\
\hline National Audit (1997) & $84 \%$ & $75 \%$ & - & - \\
\hline $\begin{array}{c}\text { Net kovski et al } \\
\text { (2006) }^{126}\end{array}$ & $87 \%$ & - & $\begin{array}{c}\text { Ant- } 70.5 \% \\
\text { Post- } 74.3 \%\end{array}$ & $58.7 \%$ \\
\hline $\begin{array}{c}\text { Chopra H. et al } \\
(2006)^{114}\end{array}$ & $83 \%$ & - & $86 \%$ & - \\
\hline $\begin{array}{c}\text { Venkatraman V et al } \\
(2013)^{129}\end{array}$ & $\begin{array}{c}\text { Significant } \\
\text { Improvement }\end{array}$ & - & $\begin{array}{c}\text { Significant } \\
\text { Improvement }\end{array}$ & - \\
\hline Present Study & $76.93 \%$ & $81.27 \%$ & $73.41 \%$ & $39.68 \%$ \\
\hline
\end{tabular}

The symptoms of CRS had remarkable improvement after FESS, signifying the effectiveness of this surgery.

In the present study, both group-A and group-B have shown good symptomatic improvement post-operatively in total SNOT score comparison. The was statistically significant difference between the group $A \& B$ with respect to change in SNOT total score from pre to post-operative period $(p=0.0002$, table-3). Group A showed better improvement in rhinologic domain whereas group $B$ showed better improvement in ear and facial domain. In sleep and psychologic domains, both the groups showed similar post operative improvement.

In all four domains of SNOT both groups have shown good symptomatic improvement post-operatively. In studies by Pynnonen et al (2009) [16] and Browne JP et al (2007) [9], they have shown that SNOT-20 as most widely used quality of life instruments for sinonasal conditions and validation studies have supported dividing SNOT in four domains namely- 
rhinologic, ear \&facial, sleep and psychological domains. The two constructs (rhinologic, ear \& facial domains) address symptoms and two others (sleep and psychological domains) address aspects of health related quality of life. The above 2 studies show effectiveness of FESS in CRS patients and the efficacy of FESS has been established by many other studies with large no of patients [10]. Other studies by Net kovski et al (2006) [13], Chopra H. et al (2006) [14], Venkatraman V et al (2013) [15] revealed significant symptomatic improvement after FESS and its efficacy in CRS patients.

\section{Conclusion}

Symptomatically patients show good improvement after FESS in SNOT total score as well as in all the 4 domains of SNOT. These studies have shown improvement in all the four domains of SNOT and that such patient reported outcome measures are clinically meaningful and scientifically sound and also help clinicians for more effective counseling about quality of life impact after operative intervention. FESS is a gold standard procedure for CRS with good efficacy.

\section{References}

1. Bhattacharya N. The economic burden and symptom manifestations of chronic rhinosinusitis. American journal of rhinology. 2003; 17(1): 27-32.

2. ECAB clinical update Otorhinolaryngology. Anirban Biswas, Santoshkacker, Mohan Kameswaram, Kirtane, VP Sood. 2012: 1-2.

3. Khalil H, Nunez DA. Functional Endoscopic Sinus Surgery for chronic rhinosinusitis. Conchrane database of Systematic Reviews. 2006; (3): 4-5.

4. Helal M, Messiha N, Amayem A, el-Maghraby A, Elsherif Z, et al. Intraoperative mitomycin- $C$ versus postoperative topical mitomycin-C drops for the treatment of pterygium. Ophthalmic Surg Lasers. 1996; 27(8): 674-8.
5. Ingrams DR, Volk MS, Biesman BS, Pankratov MM, Shapshay SM. Sinus surgery: does mitomycin C reduce stenosis? Laryngoscope. 1998; 108(6): 883-6.

6. Hessler JL, Piccirillo JF, Fang D, Vlahiotis A, Banerji A, et al. Clinical outcomes of chronic rhino sinusitis in response to medical therapy: Results of a prospective study. Am J Rhinol. 2007; 21: 10-18.

7. Robinson $S$, Douglas $R$, Wormald PJ. The relationship between atopy and chronic rhinosinusitis. Am J Rhinol. 2006; 20: 625-628.

8. Piccirillo JF, Merritt MG, Richards ML. Psychometric and clinimetric validity of the 20-Item Sino-Nasal Outcome Test (SNOT-20). Otolaryngol Head Neck Surg. 2002; 126: 41-4.

9. Browne JP, Hopkins C, Slack R, Cano SJ. The Sino-Nasal Outcome Test (SNOT): Can we make it more clinically meaningful? Otolaryngol Head Neck Surg. 2007; 136: 736-741.

10. Murthy $P$, Bannerjee $S$. Predictive Factors for a good outcome following endoscopic sinus surgery. Indian J Otolaryngol Head Neck Surg. 2013; 276-282. doi: 10.1007/s12070-011-0432-2

11. Harkens $P$, Brown $P$, Fowler $S$, Topham J. A national audit of sinus surgery. Results of the Royal College of Surgeons of England comparative audit of ENT surgery. ClinOtolaryngol. 1997; 22(2): 147-51. doi: 10.1111/ j.1365-2273.1995.tb00020.x

12. Hopkins C, Browne JP, Slack R, Lund V, Topham J, et al. The national comparative audit of surgery for nasal polyposis and chronic rhinosinusitis. ClinOtolaryngol. 2006; 31(5):390-8. doi: 10.1111/j.1749-4486.2006.01275.x

13. Netkovski J, Sirgovska B. The impact of functional endoscopic sinus surgery on symptoms in chronic rhinosinusitis. Contributions, Sec Biol. Med.Sci XXVII/2. 2006: 167-174.

14. Chopra $\mathrm{H}$, Khurana AS, Munjal M, Due K. Role of FESS in Chronic sinusitis. Ind J of Otolaryngol head neck Surgery. 2006; 58(2): 137-140. doi: 10.1007/ BF03050768

15. Venkatraman V, Balasubramanian D. Gopalkrishnan S, Saxena SK, Shanmugasundram N. Topical Mitomycin C in Functional endoscopic sinus surgery. Eur Arch Otorhinolaryngol. 2012; 269(7): 1791-4. doi: 10.1007/s00405-011-1870-x

16. Pynnonen MA, Kim HM, Terrell JE. Validation of Sino-Nasal Outcome Test 20(SNOT-20) domains in nonsurgical patients. AmericanJournal of Rhinology \& Allergy. 2009; 23: 40-45. doi: 10.2500/ajra.2009.23.3259 